\title{
Psicologias Antirracistas: Desafios Epistemológicos, Metodológicos e Ético-Políticos
}

\section{Anti-racist Psychology: Epistemological, Methodological and Ethical-Political Challenges}

\section{Psicologías Antirracistas: Desafíos Epistemológicos, Metodológicos y Ético-Políticos}

\author{
Míriam Cristiane Alves ${ }^{1}$ \\ ${ }^{1}$ Universidade Federal de Pelotas, RS, Brasil. \\ Eliane Silvia Costa ${ }^{2}$ \\ ${ }^{2}$ Universidade Federal da Bahia, BA, Brasil. \\ Marilda Castelar ${ }^{3}$ \\ ${ }^{3}$ Escola Bahiana de Medicina e Saúde Pública, BA, Brasil.
}

A presente edição especial da Revista Psicologia: Ciência e Profissão desafia-se a transitar por encruzilhadas teórico-epistemológicas e metodológicas sobre Psicologias Antirracistas e a assumir um caminho ético-político de enfrentamento ao racismo em diferentes campos de práticas e de construção do conhecimento, na defesa da igualdade racial.

Cabe lembrar que, em 2002, a Comissão Nacional de Direitos Humanos do Conselho Federal de Psicologia (CFP) lançou - durante o Fórum Social Mundial, em Porto Alegre/RS -, a campanha $O$ preconceito racial humilha, a humilhação social faz sofrer, que propôs, pela primeira vez, um debate nacional sobre o racismo no âmbito do Sistema Conselhos. Além disso, o CFP publicou a Resolução no 18/2002, que estabelece normas de atuação para psicólogas e psicólogos em relação ao preconceito e à discriminação racial. A despeito da pauta do enfrentamento ao racismo ter sido acolhida pelo Sistema Conselhos de Psicologia, ainda havia, naquele contexto, uma dificuldade importante quanto à compreensão do racismo como estruturante da sociedade brasileira e, consequentemente, da produção de subjetividade de pessoas negras e brancas.

Assim, naquele ano, foi publicado o número 22.4 da referida revista, tendo como eixo central os trabalhos vencedores do Prêmio Monográfico Arthur Ramos, cujo tema tratou da pluralidade étnica e cultural da nação brasileira. Ainda que nela haja artigos que versam criticamente sobre racismo e o mito da democracia racial, a íntegra daquela edição não se propôs a discutir conceitos como raça e racismo no campo psi, tampouco a discutir sobre os efeitos do racismo na produção de subjetividade de pessoas negras e brancas. É importante salientar que, em contexto brasileiro, um conjunto de intelectuais negras já estavam produzindo conhecimento nesse campo, a exemplo das obras: Atitudes raciais de pretos e mulatos em São Paulo, de Virgínia Leone Bicudo (2010/1945); Tornar-se Negro: as vicissitudes de identidade do negro brasileiro em ascensão social, de Neusa Santos Souza (1983); Racismo e Sexismo na Cultura Brasileira, de Lélia Gonzales (1984); e Pactos narcísicos no racismo: branquitude e poder nas organizações empresariais e no poder público, de Maria Aparecida da Silva Bento (2002a).

Quase duas décadas se passaram. Desde antes e ainda hoje, o contexto histórico e político do país demanda da Psicologia Brasileira um posicionamento ético-político de enfrentamento aos discursos e práticas que mantêm as estruturas de saber/poder da modernidade/colonialidade, fundadas na ideia de raça que perpetua a hierarquização do humano (Quijano, 1997; 2010); e que atualizam a racialidade como dispositivo de saber/poder, fazendo alusão ao que ressalta Sueli Carneiro (2005). 
Somos sabedoras e sabedores de que raça "não passa de uma ficção útil, de uma construção fantasista ou de uma projeção ideológica", que atuou na edificação do poder do hemisfério ocidental, que se considerava - e de algum modo ainda se considera -, "o centro do globo, o país natal da razão, da vida universal e da verdade da Humanidade" (Mbembe, 2017, p. 27). Assim, com a união entre raça e cor - representação forjada e mantida no imaginário social a partir do século XVI -, a raça foi usada como justificativa para o colonialismo e a hegemonia eurocêntrica (Quijano, 2010).

A partir, principalmente, do século XIX, a noção corriqueira e arraigada de hierarquização racial tornou-se também objeto de estudos das ciências, notadamente da antropologia e da medicina europeias. A ciência (ou melhor, uma pseudociência) tornou-se, então, uma das mais importantes ferramentas para a perpetuação do racismo (Munanga, 1986, Schwarcz, 1987, 1994). Com o seu aval, a suposta inferiorização de pessoas negras tornou-se verdade (ideológica) cientificamente comprovada. De acordo com Kabengele Munanga, a atitude racista e o discurso pseudocientífico tinham como função:

descobrir e pôr em evidência as diferenças entre colonizador e colonizado, valorizá-las, em proveito do primeiro e em detrimento do último e levá-las ao absoluto, afirmando que são definitivas, e agindo para que assim se tornem. A desvalorização e a alienação do negro estende-se a tudo o que toca a ele: o continente, os países, as instituições, o corpo, a mente, a língua, a música, a arte etc. (Munanga, 1986, p. 21).

Nessa mesma direção, segundo Frantz Fanon (2006), o colonialismo europeu efetivou mundialmente a hierarquia e a dominação racial das pessoas brancas em relação às negras. Trata-se de um sistema de exploração e dominação cuja violência é dada em essência, haja vista que o colonizador atua na perspectiva de dominar e explorar a existência daquelas e daqueles que vivem no território colonizado.

A colonialidade do poder consolida uma "concepção de humanidade segundo a qual a população do mundo diferencia-se em inferiores e superiores, irracionais e racionais, primitivos e civilizados, tradicionais e modernos" (Quijano, 2010, p. 86). Ela vai além dos limites e particularidades do colonialismo histórico, como algo que não desaparece mesmo após uma suposta independência ou descolonização dos povos colonizados; e expressa um modelo hegemônico global que articula raça, trabalho, subjetividades, sexualidade e contextos geopolíticos de acordo com a necessidade do capital (Quijano, 1997, 2010).

Nessa perspectiva, fica evidente a existência do que Sueli Carneiro (2005) denomina de dispositivo de racialidade, que opera e atualiza-se em nossa sociedade, configurando a racialidade como um domínio que produz saberes, poderes e subjetividades com repercussões em diferentes dimensões da vida; tanto quanto torna notório que há intersecção entre diferentes estruturas de dominação, com destaque ao racismo e sexismo. Afinal, como enfatizou Lélia Gonzales (1984, p. 224), a articulação entre racismo e sexismo "produz efeitos violentos sobre a mulher negra em particular".

O conceito de interseccionalidade (Crenshaw, 2002) possibilita que compreendamos que cada sistema de opressão (racismo, classismo e sexismo) está inscrito dentro do outro, é constituído pelo outro e que a dominação, ao privilegiar algumas pessoas e golpear outras, privilegia e fere não por um sistema ou por outro, mas pela intersecção entre eles: avilta-a por ser mulher negra, pobre e quilombola ao mesmo tempo, privilegia-o por ser homem branco, rico e citadino, ao mesmo tempo, por exemplo.

Se o racismo perpetua o privilégio branco (Hasenbalg, 2005/1979), isso é, a manutenção (enganosa) da superioridade branca, da branquitude (Bento, 2002a, 2002b), racismo, classismo e sexismo interseccionados possibilitam que a branquitude seja vivida por homens brancos heterossexuais às custas da exploração de pessoas negras, por exemplo.

A dominação interseccionada golpeia direitos civis, sociais, políticos da população negra e o efeito pode ser tão profundo e devastador que, muitas vezes, alcança a dimensão íntima da pessoa: afeta o direito a pertencer à história de um povo, de uma comunidade, afeta o direito de ser humano, de existir, de ter tranquilidade. Como mencionou Maria Lúcia da Silva (2004, p. 220): 'O racismo sobrevive num 'vir a ser' interminável. Você (a pessoa negra) dorme e acorda, e ele está presente".

Situações como essas podem ser dilacerantes. Isso não quer dizer que seus efeitos sejam irreversíveis nem que as pessoas historicamente oprimidas não criem recursos para confrontar tantas situações 
de aviltamento vividas diariamente, mas aguentar o massacre da dominação requer força considerável (Collins, 2016). A potência de vida amplia-se quando a pessoa entende criticamente como sistemas de dominação atuam na sua própria vida (Kilomba, 2019).

Apesar de os sistemas de dominação serem interseccionados, cada um deles tem especificidades históricas e conceituais. Nesta edição especial da Revista Psicologia: Ciência e Profissão destacamos o racismo, mesmo porque ele é demasiadamente negado no Brasil, o que redunda dizer que há psicólogas e psicólogos que não analisam, a partir de um horizonte histórico amplo, a conjuntura nacional tendo como lastro o racismo e não fazem nexo entre o sofrimento vivido pela população negra e esse sistema de dominação.

Ressaltamos que não há nenhum marcador genético que ateste a existência da raça biológica, no entanto, há raça social (Guimarães, 1999): afinal, fomos e somos forjados por uma violência estrutural decorrente de um projeto de dominação e exploração colonial, cuja raça e o "racismo cotidiano" (Kilomba, 2019, p. 78) produzem efeitos sobre a vida material e a construção subjetiva de pessoas negras e brancas. Nas palavras de Grada Kilomba:

O racismo cotidiano refere-se a todo vocabulário, discursos, imagens, gestos, ações e olhares que colocam o sujeito negro e as Pessoas de Cor não só como "Outra/o" - a diferença contra a qual o sujeito branco é medido - mas também como Outridade, isto é, como a personificação dos aspectos reprimidos na sociedade branca (Kilomba, 2019, p. 78).

Com o propósito de dar o devido lugar à discussão sobre as relações raciais no campo psi, esta edição especial está organizada em cinco encruzilhadas: na primeira, buscamos visibilizar construções acadêmicas que abordam a relação entre violência estrutural, projeto colonial e produção de subjetividade na sociedade brasileira, o que exige uma análise que leve em consideração um horizonte histórico mais amplo, como, de algum modo, é apresentado pelos artigos Violência civilizacional e colonial no olhar de Frantz Fanon e Sigmund Freud e Uma lei contra o crime escravista e o mal-estar da abolição. Horizonte histórico que permite colocar em evidência o efeito genocida e epistemicida do racismo cotidiano nas práticas e fazeres psicológicos.
Na segunda encruzilhada, com o intuito de pôr em discussão a produção de subjetividade de sujeitos racializados, visibilizar e denunciar a violência racista que psicólogas e psicólogos reproduzem em seus contextos de prática profissional, apresentamos os artigos Psicologia e Racismo: as heranças da clínica psicológica, Estilhaçando a máscara do silenciamento: movimentos de (re)existência de estudantes negros/negras e corpo, cultura e subjetividade: uma abordagem psicológica da normatividade branca que trazem pistas importantes para a Psicologia como ciência e profissão. Os dois primeiros artigos resultam de pesquisas empíricas que problematizam, especialmente, a escuta clínica da violência racista por psicólogas e psicólogos. O terceiro artigo trata-se de um ensaio que problematiza sociedades racializadas e a consequente produção de subjetividades racializadas, levando em conta relações entre corpo, cultura e subjetividade.

A terceira encruzilhada evidencia situações de criminalização e violação de direitos de jovens negros, problematizando a racionalidade necropolítica de dispositivos de segurança pública que acabam por produzir a segregação e o genocídio de vidas racializadas, como apresentado no artigo Dispositivo de segurança e racionalidade necrobiopolítica: narrativas de jovens negros de Fortaleza, resultado de uma pesquisa empírica.

Quanto à quarta encruzilhada, nela são apresentadas duas experiências de pesquisas-intervenção com jovens, evidenciando as potencialidades deles no enfrentamento ao racismo. $\mathrm{O}$ artigo Como quebrar os padrões sociais?: o racismo no cotidiano de jovens pesquisadores aposta na construção de uma metodologia de pesquisa em que jovens estudantes do ensino médio são instigados a construir uma investigação sobre a presença e o enfrentamento ao racismo institucional em uma escola pública estadual. Tal metodologia promoveu discussões sobre relações raciais no cotidiano escolar e deslocamentos quanto ao lugar que esses jovens ocupam na construção e descolonização de saberes. Já o artigo Afetividade no território quilombola: uma práxis possível da psicologia coloca em discussão a potencialidade de crianças e jovens quilombolas como sujeitos políticos em sua comunidade. A afetividade foi tomada como uma potência para o trato da dimensão política da vida que possibilita o enfrentamento ao racismo cotidiano e à produção de espaços de liberdade. 
Por fim, a quinta encruzilhada chama atenção para os efeitos do racismo cotidiano no mundo dos esportes e para a necessidade de profissionais de psicologia atentarem-se para a supremacia branca neste contexto. O artigo Esporte, psicologia e racismo: é possível uma psicologia do esporte antirracista? problematiza a lacuna acadêmica referente à intersecção entre esporte, psicologia e relações raciais, bem como a atuação profissional em Psicologia do Esporte no que se refere ao papel de psicólogas e psicólogos diante do racismo cotidiano, questionando se é possível uma Psicologia do Esporte Antirracista.

Importante salientar que, nos últimos anos, o CFP tem construído ações que buscam a problematização, a abertura de fissuras e, quiçá, o desmantelamento das estruturas de saber e de poder da sociedade brasileira - por meio da Psicologia enquanto ciência e profissão -, que se fundaram na ideia de raça e na hierarquização do humano ditando quem deve viver ou morrer. Esta edição especial da Revista Psicologia: Ciência e Profissão se desafiou a acumular empírica e teoricamente sobre as relações raciais no âmbito das ciências psicológicas.

Não obstante, ainda necessitamos ultrapassar a ideia de que o racismo cotidiano é um tema transversal e que, por tal compreensão, não é (ou não deve ser) pensado e tratado em todo e qualquer campo da Psicologia. Necessitamos chegar à concepção de que o racismo é uma episteme que estrutura nossa sociedade e que, por esse motivo, necessita estar na centralidade de diferentes campos psicológicos. Ou seja, o enfrentamento ao racismo necessita ser estruturante, e não transversal, de toda e qualquer ação ético-política da Psicologia enquanto ciência e profissão para assim produzirmos Psicologias Antirracistas, considerando as diferentes epistemologias e metodologias que a constitui.

\section{Referências}

Bento, M. A. S. (2002a). Pactos narcísicos no racismo: Branquitude e poder nas organizações empresariais e no poder público [Tese de doutorado]. Instituto de Psicologia da Universidade de São Paulo.

Bento, M. A. S. (2002b). Branqueamento e branquitude no Brasil. In I. Carone \& M. A. S. Bento (Orgs.), Psicologia social do racismo: estudos sobre branquitude e branqueamento no Brasil (pp. 25-58). Vozes.

Bicudo,V. L. (2010). Atitudes raciais de pretos e mulatos em São Paulo (M. C. Maio, Org.). Editora Sociologia e Política. (Trabalho original publicado em 1945)

Carneiro, A. S. (2005). A construção do outro como não ser como fundamento do ser [Tese de doutorado]. Faculdade de Educação da Universidade de São Paulo.

Collins, P. H. (2016). Aprendendo com a outsider within: A significação sociológica do pensamento feminista negro. Revista Sociedade e Estado, 31(1), 99-127.

Crenshaw, K. (2002). Documento para o encontro de especialistas em aspectos da discriminação racial relativos ao gênero. Revista Estudos Feministas, 10(1), 171-188.

Fanon, F. (2006). Os condenados da terra. UFJF.

Gonzales, L. (1984). Racismo e sexismo na cultura brasileira. Revista Ciências Sociais Hoje[Anuário de Antropologia, Política e Sociologia], 223-244.

Guimarães, A. S. A. (1999). Racismo e anti-racismo no Brasil. FUSP; Editora 34.

Hasenbalg, C. A. (2005). Discriminação e desigualdades raciais no Brasil. Graal; UFMG/Iuperj/Ucam. (Trabalho original publicado em 1979)

Kilomba, G. (2019). Memórias de Plantação: Episódios de racismo cotidiano. Cobagó.

Mbembe, A. (2017). Crítica da razão negra. Editora Antígona.

Munanga, K. (1986). Negritude: Usos e sentidos. Ática.

Quijano, A. (1997). Colonialidad del poder, cultura y conocimiento en América Latina. Anuario Mariateguiano, 9(9), 113-122.

Quijano, A. (2010). Colonialidade do poder e classificação social. In B. S. Santos \& M. P. Meneses (Orgs.), Epistemologias do Sul (pp. 84-130). Cortez. 
Schwarcz, L. M.. (1987). Retrato em branco e preto: Jornais, escravos e cidadãos em São Paulo no final do século XIX. Companhia das Letras.

Schwarcz, L. M. (1994). O espetáculo das raças. Companhia das Letras.

Silva, M. L.. (2004). O preconceito racial humilha, a humilhação faz sofrer: Reflexões sobre a construção psíquica do sujeito negro. In Conselho Federal de Psicologia (Org.), Psicologia e direitos humanos: Subjetividade e exclusão (pp. 217-222). Casa do Psicólogo.

Souza, N. S. (1983). Tornar-se negro: As vicissitudes de identidade do negro brasileiro em ascensão social. Graal.

\section{Míriam Cristiane Alves}

Professora Adjunta do curso de Psicologia da Universidade Federal de Pelotas (UFPel), colaboradora do Programa de Pós-Graduação em Psicologia Social e Institucional da Universidade Federal do Rio Grande do Sul (UFRGS) e coordenadora do Núcleo de Estudos e Pesquisas É'LÉÉKO: Agenciamentos Epistêmicos Antirracistas e De(s) coloniais, Pelotas/Porto Alegre - RS. Brasil.

E-mail: olorioba.miriamalves@gmail.com

(1) https://orcid.org/0000-0002-4318-1927

\section{Eliane Silvia Costa}

Professora Adjunta do Instituto de Psicologia da Universidade Federal da Bahia (UFBA), pesquisadora colaboradora do Instituto de Psicologia da Universidade de São Paulo (IP-USP) e pesquisadora associada ao Laboratório de Estudos em Psicanálise e Psicologia Social do Instituto de Psicologia da Universidade de São Paulo (LAPSO/IP-USP), Salvador - BA. Brasil.

E-mail: eliane.silvia@ufba.br

(1) https://orcid.org/0000-0002-1487-3473

\section{Marilda Castelar}

Professora Adjunta do curso de Psicologia, do Mestrado profissional de Psicologia e Intervenções em Saúde e do Mestrado em Tecnologias em Saúde da Escola Bahiana de Medicina e Saúde Pública, coordenadora do Grupo de Pesquisa Psicologia Diversidade e Saúde e editora da Revista Psicologia Diversidade e Saúde, Salvador - BA. Brasil. E-mail: marildacastelar@bahiana.edu.br

(1) https://orcid.org/0000-0003-1628-6739

Como citar: Alves, M. C., Costa E. S., \& Castelar, M. (2020). Psicologias antirracistas: Desafios epistemológicos, metodológicos e ético-político. Psicologia: Ciência e Profissão, 40 (n.spe), 1-5. https://doi.org/10.1590/

1982-3703003052019

How to cite: Alves, M. C., Costa E. S., \& Castelar, M. (2020). Anti-racist psychology: Epistemological, methodological and ethical-political challenges. Psicologia: Ciência e Profissão, 40 (n.spe), 1-5. https://doi.org/10.1590/

$1982-3703003052019$

Cómo citar: Alves, M. C., Costa E. S., \& Castelar, M. (2020). Psicologías Antirracistas: Desafíos Epistemológicos, Metodológicos y Ético-Políticos. Psicologia: Ciência e Profissão, 40 (n.spe), 1-5. https://doi.org/10.1590/ 1982-3703003052019 